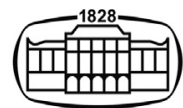

AKADÉMIAI KIADÓ

Acta Chromatographica

34 (2022) 2, 203-209

DOl:

$10.1556 / 1326.2021 .00907$

(c) 2021 The Author(s)

\section{ORIGINAL RESEARCH} PAPER

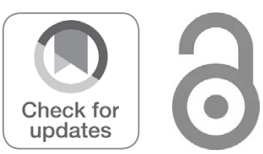

\title{
RP-HPLC stability-indicating method for simultaneous determination of sodium valproate, methylparaben and propylparaben in oral solution
}

\author{
HISHAM ELREFAY ${ }^{1}$, OMNIA A. ISMAIEL ${ }^{2}$, \\ WAFAA S. HASSAN ${ }^{2}$, ABDALLA SHALABY ${ }^{2}$ and ALI FOUAD ${ }^{3 *} \bullet$ \\ ${ }^{1}$ Simco Pharmaceutical Industries, 6th of October, Egypt \\ ${ }^{2}$ Department of Analytical Chemistry, Faculty of Pharmacy, Zagazig University, Egypt \\ ${ }^{3}$ Department of Pharmaceutical Chemistry, Faculty of Pharmacy, Al-Azhar University, 71524, \\ Assiut, Egypt
}

Received: March 20, 2021 • Accepted: May 18, 2021

Published online: June 15, 2021

\begin{abstract}
A new, sensitive, stability-indicating reversed-phase HPLC method was validated and applied for the simultaneous quantitation of sodium valproate and two paraben preservatives; methylparaben, and propylparaben in the liquid dosage form. Stability tests were carried out through exposure of the analyte's solution to stress conditions. Separation of the analytes was achieved on (waters) C18 Column $(150 \mathrm{~mm} \times 3.9 \mathrm{~mm}, 5 \mu \mathrm{m})$. A mixture of $0.05 \mathrm{M}$ monobasic potassium phosphate $\mathrm{pH} 3.5$ and acetonitrile $(50: 50 ; \mathrm{v} / \mathrm{v})$ was applied at $1.5 \mathrm{ml} / \mathrm{min}$ flow rate and UV detection wavelength at $210 \mathrm{~nm}$. The degradation products and the analytes were completely separated. The linearity was performed in the range of 50-150\% from a target concentration of $10 \mu \mathrm{g} / \mathrm{ml}$ propylparaben, $90 \mu \mathrm{g} / \mathrm{ml}$ methylparaben, and $2.88 \mathrm{mg} / \mathrm{ml}$ sodium valproate with a coefficient correlation $\left(\mathrm{R}^{2}\right) 1.0$ for methylparaben, propylparaben and sodium valproate. The validation results of the suggested method were in a good agreement with ICH guidelines. Application of the proposed method for analysis of liquid dosage forms was successfully carried out in the routine quality control process.
\end{abstract}

\section{KEYWORDS}

methylparaben, propylparaben, sodium valproate, stability-indicating RP-HPLC, stress degradatiocn

\section{INTRODUCTION}

Methylparaben [MP], methyl 4-hydroxybenzoate (Fig. 1a), has a molecular weight of 152.156 $\mathrm{g} / \mathrm{mol}$. propylparaben [PP], chemically is Propyl 4- hydroxybenzoate (Fig. 1b), with a molecular weight of $180.2 \mathrm{~g} / \mathrm{mol}$ [1]. Both MP and PP are members of Parabens group which are commonly used as preservatives in pharmaceutical formulation, as well as food and cosmetic products due to their anti-fungal and antibacterial activity $[2,3]$. The parabens proved efficiency over a wide $\mathrm{pH}$ range [4]. Addition of preservatives to liquid preparations; which are susceptible to microbial growth; is needed to prevent the degradation and alteration of the products [5]. MP and PP were assayed by titration methods in USP which require a long time

Corresponding author. Tel: $+201004379068$.

E-mail: Alifouad247@gmail.com; Alifouad.team@azhar.edu.eg for sample preparation [6]. Parabens were assayed by RP-HPLC methods in pharmaceutical products and cosmetics $[3,5,7-9]$.

Sodium valproate [VLP] is chemically sodium-2-propyl pentanoate (Fig. 1c) [1]. It is the first line drug used in the treatment of primary generalized, partial, and myoclonic seizures. VLP mode of action is to increase the synthesis and decrease the metabolism of gammaaminobutyric acid, thus stabilizing the electrical activity in the brain $[10,11]$. VLP is official 
<smiles>COC(=O)c1ccc(O)cc1</smiles><smiles>CCCOC(=O)c1ccc(O)cc1</smiles>

Fig. 1. Chemical structure of (A): methylparaben, (B): propylparaben and (C): sodium valproate

in both USP and BP which have adopted GC and HPLC methods for quantitative analysis of this drug in formulations, respectively $[1,6]$. The literature reported different analytical methods for the quantification of VLP in biological matrices either alone or in combination with other drugs. These methods include HPLC [12-14], UV-spectrophotometry [15] and fluorometry [16], and gas chromatography $[17,18]$.

European Medicine Agency (EMA) mentioned that the addition of antimicrobial preservatives in a medical formulation requires special justification, so the release specifications for a finished product should include both identification and content determination tests for each antimicrobial preservative included in the formulation [19]. Parabens preservatives are considered as an integral part of VLP oral solution. There is no reported HPLC method for the simultaneous determination of VLP in its oral syrup with parabens, so it was important to develop a HPLC method capable of estimating both the analyte and the preservatives.

Because of its unique features, as it is economically and environmentally benign than other methods, RP-HPLC method was used here [21-26]. The major advantage of the proposed method is that the assay of sodium valproate and preservatives can be achieved in presence of their stress degradation products on a single chromatographic system with UV detection without the need for prior derivatization. According to the obtained results, we suggest using the proposed stability indicating method for quality control purposes. To assess the reproducibility and applicability of the suggested method, validation was carried out as per ICH guidelines [20].

\section{EXPERIMENTAL}

\section{Reagents and chemicals}

MP and PP were purchased from Merck (Germany) and VLP was purchased from (SCI) pharmatech, Inc Taiwan. Placebo was prepared in the lab without addition of active ingredients and preservatives. 2-isopropyl pentanoic acid was purchased from El-Gomhouria Company for Trading chemicals and medical supplies, Egypt. All chemicals used were of HPLC grade: Acetonitrile was purchased from Scharlu (Barcelona, Spain), and orthophosphoric acid was purchased from Merck. Daviken ${ }^{\circledR}$ (Amoun Pharma, Egypt) oral solution was purchased from the local market. Milli-Q
(Millipore Corporation, Billerica, MA, USA) ultra-pure water was used.

\section{Instrumentation and chromatographic conditions}

The HPLC system (Shimadzu LC-10AD vp, Japan) was equipped with an auto-sampler, quaternary HPLC Pumps, Dual lamp Absorbance Detector and In-Line Degasser ISA Card. Data acquisition was performed on LC solution software. The HPLC separation and quantitation were achieved on Waters C18 Column $(150 \mathrm{~mm} \times 3.9 \mathrm{~mm}, 5 \mu \mathrm{m}$ particle size) was used for analytical separation. The mobile phase consisted of $0.05 \mathrm{M}$ monobasic potassium phosphate $\mathrm{pH} 3.5$, and acetonitrile $(50: 50 ; \mathrm{v} / \mathrm{v})$. The flow was adjusted to 1.5 $\mathrm{ml} / \mathrm{min}$ and the detector was set at $210 \mathrm{~nm}$.

$0.05 \mathrm{M}$ Monobasic potassium phosphate was prepared by dissolving $6.8 \mathrm{~g}$ of potassium dihydrogen phosphate per liter of distilled water, the $\mathrm{pH}$ was adjusted into 3.5 using $0.1 \mathrm{M}$ orthophosphoric acid and filtered through $0.45 \mu \mathrm{m}$ filter before use. Metrohm $827 \mathrm{pH}$ meter (Switzerland) is used for adjusting the mobile phase $\mathrm{pH}$.

\section{Preparation of standard solutions}

The standard stock solutions of MP and PP were prepared by transferring $90.0 \mathrm{mg} \mathrm{MP}$ and $50.0 \mathrm{mg}$ PP into $100 \mathrm{ml}$ volumetric flasks. $90 \mathrm{ml}$ of water were added to each flask, mixed and the volume was completed with water and filtered using. $0.45 \mu$ filter to obtain a solution having a concentration of 0.90 and $0.50 \mathrm{mg} / \mathrm{ml}$ of $\mathrm{MP}$ and $\mathrm{PP}$, respectively.

A working standard solution (containing 0.09, 0.01 and $2.5 \mathrm{mg} / \mathrm{ml}$ of MP, PP, and VLP, respectively) was prepared by transferring $250.0 \mathrm{mg}$ of VLP (sodium valproate $288 \mathrm{mg}$ equivalent to $250 \mathrm{mg}$ valproic acid) standard into $100 \mathrm{ml}$ volumetric flask. $30 \mathrm{ml}$ of mobile phase were added, mixed, 10 $\mathrm{ml}$ of MP standard stock solution and $2 \mathrm{ml}$ from PP standard stock solution were transferred into the volumetric flask mixed and the volume was completed using mobile phase and filter through a $0.45 \mu$ filter. Different concentrations ranging from 50 to $150 \%$ of the above solution were prepared.

\section{Preparation of sample solutions}

The sample solution was prepared by transferring $5 \mathrm{ml}$ of Daviken oral syrup to $100 \mathrm{ml}$ volumetric flask. $50 \mathrm{ml}$ of mobile phase were added and mixed, the volume was completed using mobile phase and the solution filtered through $0.45 \mu$ filter. 


\section{Forced degradation conditions}

Acid degradation: the mixture of MP, PP, and VLP was prepared as previously described in the preparation of working standard solution but $5 \mathrm{ml}$ of $5 \mathrm{~N} \mathrm{HCl}$ were added to the analytes. The mixture was shaken for 5 minutes and left in the dark at room temperature for 1 hour, then neutralized by $5 \mathrm{ml}$ of $5 \mathrm{~N} \mathrm{NaOH}$ before completing volume into $100 \mathrm{ml}$ with the mobile phase.

Alkaline degradation: prepared by adding $5 \mathrm{ml}$ of $5 \mathrm{~N}$ $\mathrm{NaOH}$ to the mixture of MP, PP, and VLP standard solution, containing the same amounts of working standard solution, and shaken for 5 minutes and left in the dark at room temperature for 1 hour, then neutralized with $5 \mathrm{ml}$ of $5 \mathrm{~N} \mathrm{HCl}$. The volume was completed to $100 \mathrm{ml}$ with the mobile phase.

Oxidative degradation: prepared by adding $5 \mathrm{ml}$ of $30 \%$ $\mathrm{H}_{2} \mathrm{O}_{2}$ to the same concentration of a mixture of MP, PP, and VLP standard solution used in acid and alkaline degradation. The mixture was shaken for 5 minutes and left in the dark at room temperature for 1 hour, then the volume was completed to $100 \mathrm{ml}$ with the mobile phase.

\section{Validation}

The proposed analytical method was validated according to ICH guidelines with respect to certain parameters such as specificity, linearity, precision, accuracy, and system suitability[20].

\section{Stability of standard solution}

The Stability of standard solution was checked using standard solutions of MP, PP, and VLP over a period of $22 \mathrm{~h}$.

\section{RESULTS}

\section{Method development}

The present investigation reported is a new RP-HPLC method development and validation of simultaneous estimation of MP, PP, and VLP. The method developed was proceeding with wavelength selection. The optimized wavelength was $210 \mathrm{~nm}$. In order to get the optimized RP-HPLC method, various mobile percent's of monobasic potassium phosphate and acetonitrile ranged from $(90: 10 ; \mathrm{v} / \mathrm{v})$ to (10:90; v/v) were tried. $0.05 \mathrm{M}$ monobasic potassium phosphate $\mathrm{pH} 3.5$ and acetonitrile $(50: 50 ; \mathrm{v} / \mathrm{v})$ as mobile phase gave the best results. The column used was (waters) C18 Column $(150 \mathrm{~mm} \times 3.9 \mathrm{~mm}, 5 \mu \mathrm{m}$ particle size). The flow rate was adjusted to $1.5 \mathrm{ml} / \mathrm{min}$. The analysis was carried out at room temperature using $20 \mu \mathrm{L}$ as an injection volume.

\section{METHOD VALIDATION}

\section{System suitability}

System suitability parameters were defined as tests to confirm that the method can generate results of acceptable accuracy and precision. The requirements for system suitability are usually developed after method development and validation has been completed. The USP (2000) defines parameters that can be used to determine system suitability prior to analysis. The system suitability parameters like Theoretical plates $(\mathrm{N})$, Resolution (R), Tailing factor $(\mathrm{T})$ were calculated and were compared with the standard values to confirm the suitability of the developed method. Theoretical plates, resolution and tailing factor values were represented for determination of MP, PP, and VLP are reported in Table 1.

\section{System repeatability}

System repeatability results showed that RSD \% was 0.11 , 0.14 and 0.05 for MP, PP, and VLP, respectively.

\section{Selectivity}

Analysis of the oral solution confirmed selectivity of the suggested method. No interference with the target analytes was observed in presence of the excipients. The representative chromatogram of MP, PP, and VLP in Oral solution showed no interfering peaks from excipient components (Fig. 2).

\section{Linearity, LOD and LOQ}

Linearity of the method (within a given range) expresses its ability to obtain a directly proportional relationship between test results and the corresponding concentration of an analyte. Under the optimum chromatographic conditions, linearity was established by injection of a series of sample mixtures of MP, PP, and VLP at five different concentration levels; $50,75,100,125$ and $150 \%$ of the target concentration range for MP, PP, and VLP (90, 10 and 2,500 $\mu \mathrm{g} / \mathrm{ml})$; into the chromatographic system. Plotting the peak area against the corresponding concentration was used in construction of the calibration curves of each analyte. The Slope (b), intercept (a) and correlation $\mathrm{R}^{2}$ were determined. LOD is the minimum concentration that can be detected by the proposed method. It was determined from the formula; LOD = $3.3 \sigma / \mathrm{S}$, where $(\sigma)$ is SD of the intercept and $(S)$ is the slope of regression equation. LOQ is the lowest concentration which can be measured with acceptable precision and accuracy. It was calculated similarly from the equation $\mathrm{LOQ}=$ $10 \sigma / \mathrm{S}$.

Table 1. System suitability parameters for MP, PP and VLP

\begin{tabular}{lcccc}
\hline Parameters/R & MP & PP & VLP & Acceptance \\
(min.) & 1.99 & 3.91 & 4.86 & criteria \\
\hline Asymmetry & 1.243 & 1.108 & 1.063 & $\leq 2$ \\
$\begin{array}{l}\text { Resolution }\left(\mathrm{R}_{\mathrm{s}}\right) \\
\begin{array}{l}\text { Theoretical } \\
\quad \text { plates }(\mathrm{N})\end{array}\end{array}$ & - & 9.917 & 3.606 & $>2$ \\
HETP $^{*}$ & 18,023 & 29,765 & 29,171 & $>2000$ \\
\hline
\end{tabular}

"Height equivalent of a theoretical plate $(\mathrm{HETP})=\mathrm{L} / \mathrm{N}$ where $-\mathrm{L}$ is Length of the column. 

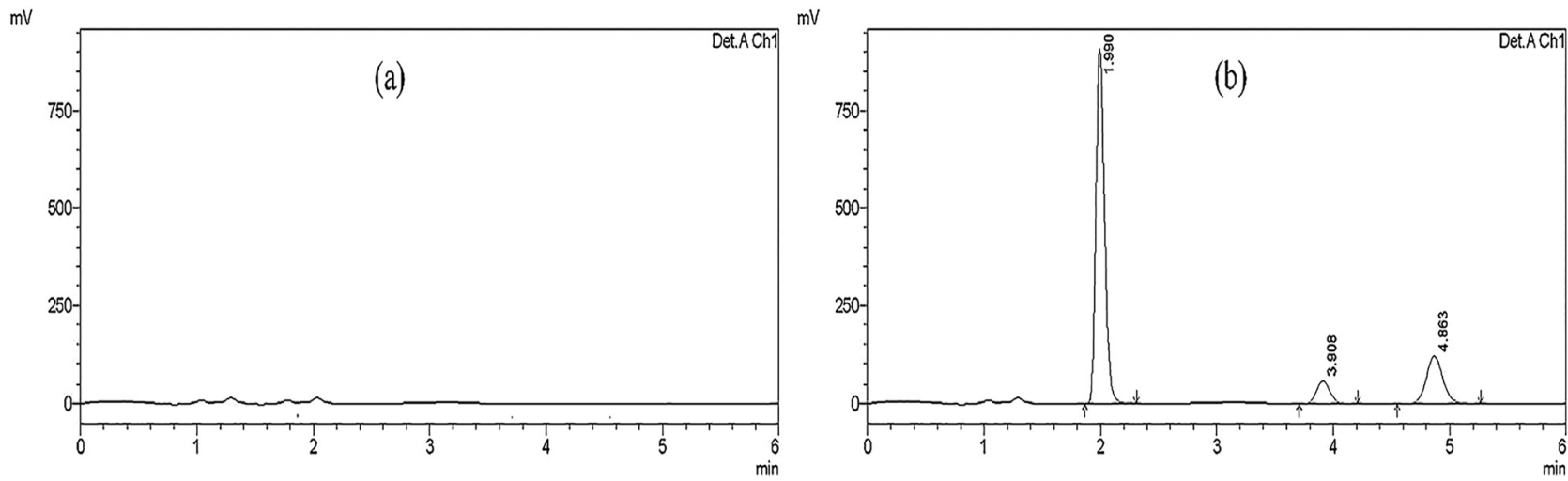

Fig. 2. Chromatograms of (A): Placebo and (B): a mixture of methylparaben, propylparaben and sodium valproate in pharmaceutical formulation

Results of the regression statistics obtained for MP, PP, and VLP are presented in Table 2. A significant correlation between the analytes concentration and peak area was observed, $\mathrm{R}^{2}=1.0$ for MP, PP, and VLP. LOD and LOQ are represented in Table 2.

\section{Precision}

Method precision was determined both in terms of repeatability; precision under the same operating conditions over a short interval of time; and intermediate precision (Ruggedness) which shows the degree of reproducibility of test results obtained by analyzing the sample under a variety of normal test conditions such as different days, analyst or instruments. In order to determine precision, six independent sample solution preparations from a single lot of formulation of MP, PP, and VLP solution (0.09, 0.01 and 2.5 $\mathrm{mg} / \mathrm{ml}$, respectively) were injected into HPLC system in triplicates on the same day (intraday precision), on three different days (inter-day precision) by the same operator and by another one (analyst to analyst precision). The retention time and peak area were determined and expressed as mean and \%RSD calculated from the data obtained.

Intraday, inter-day and analyst to analyst precision results are shown in Table 3. \%RSD values were less than $0.5 \%$ for the three analytes.

Table 2. Five level calibration graphs for MP, PP and VLP

\begin{tabular}{lccc}
\hline & \multicolumn{3}{c}{ Analyte } \\
\cline { 2 - 4 } Parameter & methylparaben & propylparaben & $\begin{array}{c}\text { sodium } \\
\text { valproate }\end{array}$ \\
\hline Linearity $(\mu \mathrm{g} /$ & $45-135$ & $5-15$ & $1,440-4,320$ \\
$\quad \mathrm{ml})$ & & & \\
LOD $(\mu \mathrm{g} / \mathrm{ml})$ & 0.34 & 0.01 & 30.38 \\
LOQ $(\mu \mathrm{g} / \mathrm{ml})$ & 1.03 & 0.03 & 92.04 \\
Slope & 51,362 & 45,867 & 405.6 \\
Intercept & 49,620 & -920.4 & 5,814 \\
$\mathrm{r}^{2}$ & 1.0 & 1.0 & 1.0 \\
$\mathrm{t}_{\mathrm{R}} \pm \mathrm{SD}(\mathrm{min})$. & $2.004 \pm 0.013$ & $3.983 \pm 0.020$ & $4.8904 \pm$ \\
& & & 0.011 \\
\hline
\end{tabular}

Table 3. The inter and intra-day precision (\%RSD) data for MP, PP and VLP

\begin{tabular}{lccc}
\hline Analyte & $\begin{array}{c}\text { Intraday } \\
\text { RSD }^{*} \%\end{array}$ & $\begin{array}{c}\text { Inter-day } \\
\text { RSD }^{*} \%\end{array}$ & $\begin{array}{c}\text { Analyst to analyst } \\
\text { RSD }^{*} \%\end{array}$ \\
\hline MP & 0.13 & 0.37 & 0.19 \\
PP & 0.14 & 0.14 & 0.26 \\
VLP & 0.20 & 0.07 & 0.19 \\
\hline
\end{tabular}

" Average of three experiments for each concentration

\section{Accuracy}

The accuracy of the methods was determined by injecting three concentrations of the sample solution into HPLC system in triplicate. 50, 100 and $150 \%$ of the target concentration were used after spiking with standard concentration of the analytes. The percentage recoveries for MP, PP, and VLP were calculated.

The results of accuracy studies were shown in Table 4; recovery values were within the accepted range.

\section{Robustness}

The robustness of the proposed methods was indicated by the constancy of the peak areas with minor changes in the experimental parameters. These parameters included: Flow rate varied at three levels $( \pm 6.6 \%)$, change in composition of

Table 4. Accuracy (\% recovery) data for sodium valproate, methylparaben and propylparaben in pharmaceutical formulation

\begin{tabular}{|c|c|c|c|}
\hline $\begin{array}{l}\text { Nominal concentration } \\
90,10 \text { and } 2,880 \mu \mathrm{g} / \mathrm{ml} \\
\text { MP, PP and VLP. }\end{array}$ & $\begin{array}{c}\mathrm{MP} \\
\% \\
\text { recovery } \\
\pm \mathrm{SD}\end{array}$ & $\begin{array}{c}\mathrm{PP} \\
\% \\
\text { recovery } \\
\pm \mathrm{SD}\end{array}$ & $\begin{array}{l}\text { VLP } \\
\% \\
\text { recovery } \\
\pm \mathrm{SD}\end{array}$ \\
\hline $50 \%$ & $\begin{array}{c}100.60 \pm \\
0.14\end{array}$ & $\begin{array}{c}100.23 \pm \\
0.15\end{array}$ & $\begin{array}{c}100.15 \pm \\
0.07\end{array}$ \\
\hline $100 \%$ & $\begin{array}{c}100.04 \pm \\
0.13\end{array}$ & $\begin{array}{c}100.53 \pm \\
0.19\end{array}$ & $\begin{array}{c}100.30 \pm \\
0.09\end{array}$ \\
\hline $150 \%$ & $\begin{array}{c}99.47 \pm \\
0.02\end{array}$ & $\begin{array}{c}100.43 \pm \\
0.04\end{array}$ & $\begin{array}{c}99.48 \pm \\
0.02\end{array}$ \\
\hline
\end{tabular}

* Average of three experiments for each concentration. 
mobile phase water $\pm 5 \%$, change in column oven temperature $\left( \pm 5^{\circ} \mathrm{C}\right)$, and change in different brand of filter paper. These minor changes did not affect the peak areas of both drugs.

\section{Stability of standard solution}

The Stability of standard solution indicates the possibility of using standard solutions of MP, PP, and VLP over a period of $22 \mathrm{~h}$ without degradation as the RSD \% of the standards was less than 1.0 for MP, PP, and VLP.

\section{Forced degradation studies}

Forced degradation studies were established by subjecting samples of MP, PP, and VLP standard solutions to degradation in $\mathrm{NaOH}, \mathrm{HCl}$ and $\mathrm{H}_{2} \mathrm{O}_{2}$. The degradation samples were analyzed using the proposed method. Minor degradations of MP, PP, and VLP ( 3.5\%) were observed under acidic conditions at room temperature. Several small degradation product peaks were observed as shown in Fig. 3. At room temperature, MP, PP, and VLP peaks showed approximately $13 \%, 11 \%$ and $11 \%$ degradation under the alkaline condition, respectively. The elution profiles of degradation products are shown in Fig. 3. Degradations of ( $\mathrm{MP} \sim 12 \%),(\mathrm{PP} \sim 8 \%)$ and $(\mathrm{VLP} \sim 7 \%)$ were also observed under oxidative conditions at room temperature. All degradation products were chromatographically resolved from target analytes the acidic degradation products were chromatographically resolved from target analytes; resolution between every two successive peaks was greater than 2 .

\section{DISCUSSION}

The present investigation reported is a novel RP-HPLC method development and validation of simultaneous estimation of MP, PP, and VLP. Mixture of MP, PP, and VLP did not estimate simultaneously before. The method developed was proceeding with optimized wavelength $210 \mathrm{~nm}$ and mobile phase consisting of $0.05 \mathrm{M}$ monobasic potassium phosphate $\mathrm{pH} 3.5$ and acetonitrile (50:50; $\mathrm{v} / \mathrm{v}$ ) In order to get the optimized RP-HPLC method. The column used was (waters) C18 Column $(150 \mathrm{~mm} \times 3.9 \mathrm{~mm}, 5 \mu \mathrm{m}$ particle size). Analysis of the oral solution confirmed selectivity of the suggested method.

A significant correlation between the analytes concentration and peak area was observed, $\mathrm{R}^{2}=1.0$ for MP, PP, and VLP. The Stability of standard solution indicates the possibility of using standard solutions of MP, PP, and VLP over a period of $22 \mathrm{~h}$ without degradation.
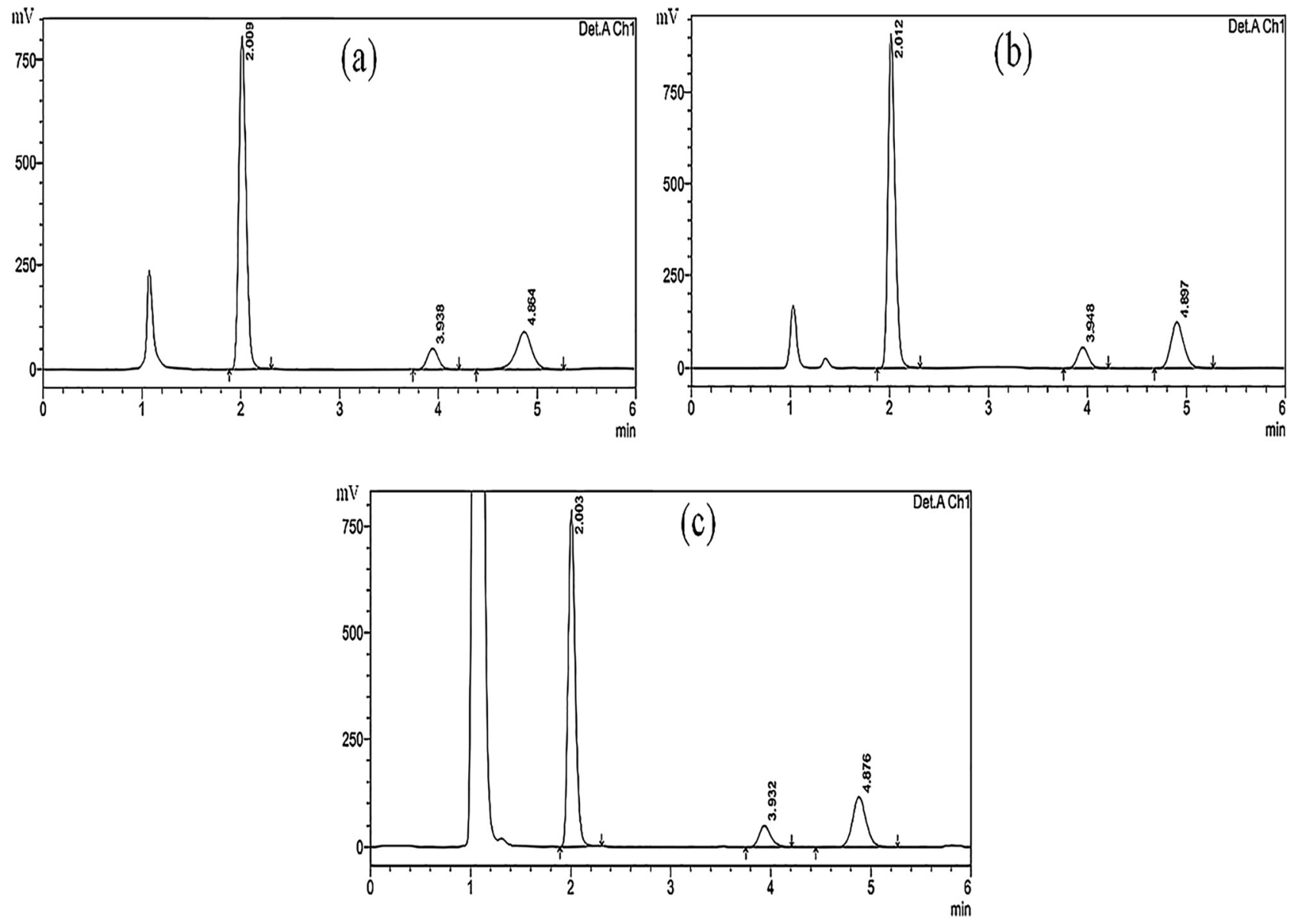

Fig. 3. Degradation chromatograms of methylparaben, propylparaben and sodium valproate using (a): $5 \mathrm{~N} \mathrm{NaOH},(\mathrm{b}): 5 \mathrm{~N} \mathrm{HCl}$ and (c): $30 \%$ $\mathrm{H}_{2} \mathrm{O}_{2}$ 


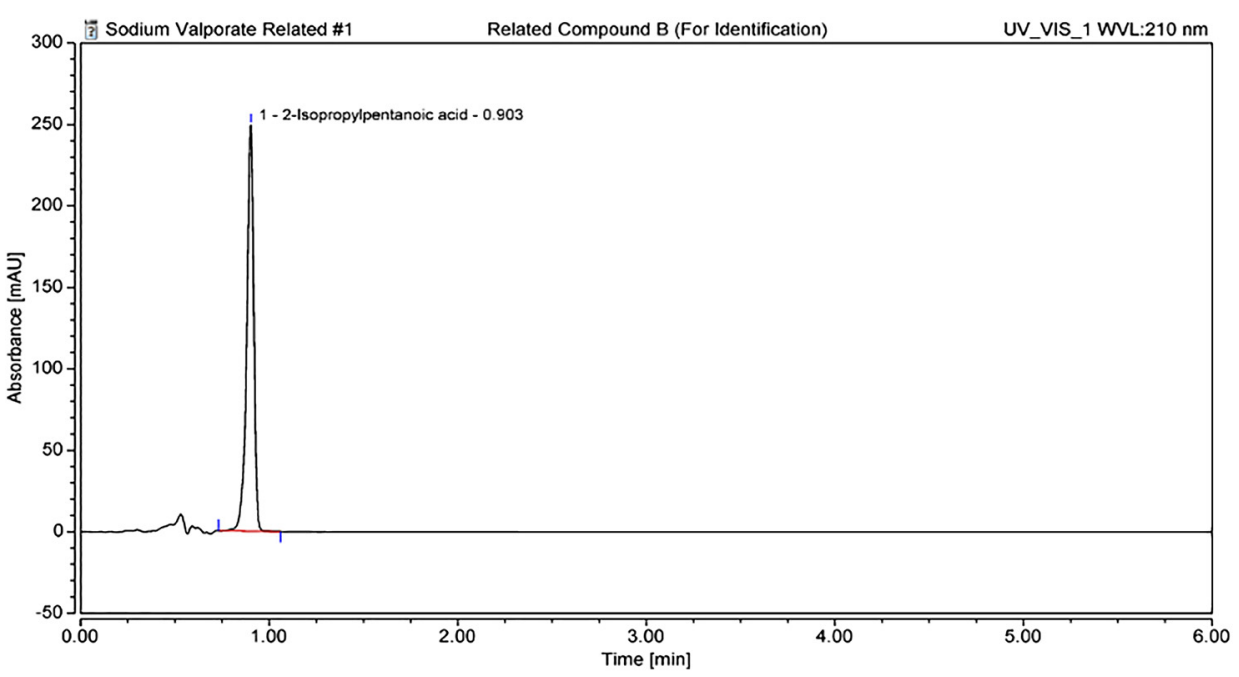

Fig. 4. Degradation chromatogram of 2-isopropylpentanoic acid, the reported degradation product of VLP

Application of the proposed method for analysis of liquid dosage forms was successfully carried out in the routine quality control process. Separation of the analytes from their degradation products was successfully achieved with high selectivity, accuracy, precision and robustness of the developed method.

Minor degradations of MP, PP, and VLP ( 3.5\%) were observed under acidic conditions at room temperature. At room temperature, MP, PP, and VLP peaks showed approximately $13 \%, 11 \%$ and $11 \%$ degradation under the alkaline condition, respectively The raw chromatograms of MP, PP, and VLP were added as additional data (supplementary material).

Standard solution of 2-isopropylpentanoic acid, the reported degradation product of VLP under the alkaline condition which is constitutional isomer of valproic acid [27] was analyzed using the proposed method as in Fig. 4.

The high selectivity, accuracy, precision and robustness of the developed method make it suitable to be used during the manufacturing process and to evaluate the quality of oral solution in the regular quality control processes.

\section{CONCLUSION}

The presented work describes a stability indicating HPLC method for analysis of MP, PP, and VLP in oral solution. Separation of the analytes from their degradation products was successfully achieved. The high selectivity, accuracy, precision and robustness of the developed method make it suitable to be used during the manufacturing process and to evaluate the quality of oral solution in the regular quality control processes.

Conflict of interests: The authors declare no conflict of interest.

\section{ACKNOWLEDGMENTS}

The authors are grateful to Simco Pharmaceutical Industries, 6 of October City, Egypt, for providing laboratory facilities to carry out this work.

\section{SUPPLEMENTARY MATERIAL}

Supplementary material to this article can be found online at https://doi.org/10.1556/1326.2021.00907

\section{REFERENCES}

1. United States Pharmacopoeia NF. USP30; United States Pharmacopoeial Convention, Inc, 2007.

2. Andersen, F. A. Final amended report on the safety assessment of methylparaben, ethylparaben, propylparaben, isopropylparaben, butylparaben, isobutylparaben, and benzylparaben as used in cosmetic products. Int. J. Toxicol. 2008, 27, 1-82. https://doi.org/10. 1177/109158180802704s01.

3. Kumar, S.; Mathkar, S.; Romero, C.; Rustum, A. M. Development and validation of a single RP-HPLC assay method for analysis of bulk raw material batches of four parabens that are widely used as preservatives in pharmaceutical and cosmetic products. J. Chromatogr. Sci. 2011, 49, 405-11.

4. Peng, X.; Adachi, K.; Chen, C.; Kasai, H.; Kanoh, K.; Shizuri, Y.; Misawa, N. Discovery of a marine bacterium producing 4hydroxybenzoate and its alkyl esters, parabens. Appl. Environ. Microbiol. 2006, 72, 5556-61.

5. Gopalakrishnan, S.; Chitra, T. A.; Aruna, A.; Chenthilnathan, A. Development of RP-HPLC method for the simultaneous estimation of ambroxol hydrochloride, cetirizine hydrochloride and antimicrobial preservatives in combined dosage form. Der Pharma Chem. 2012, 4, 1003-15. 
6. The British Pharmacopoeia; Her Majesty's Stationary Office: London, 2009.

7. Shabir, G. A. A new validated HPLC method for the simultaneous determination of 2-phenoxyethanol, methylparaben, ethylparaben and propylparaben in a pharmaceutical gel. Indian J. Pharm. Sci. 2010, 72, 421-5.

8. Kumar, N.; Vaghela, B.; Reddy, P. S.; Sangeetha, D. Development and validation of a novel stability indicating RP-UPLC method for simultaneous determination of nizatidine, methylparaben and propylparaben in oral liquid pharmaceutical formulation. Quim Nova 2012, 35, 827-31.

9. Baranowska, I.; Wojciechowska, I; Solarz, N.; Krutysza, E. Determination of preservatives in cosmetics, cleaning agents and pharmaceuticals using fast liquid chromatography. J. Chromatogr. Sci. 2013, 52, 88-94.

10. Kwan, P.; Sills, G. J.; Brodie, M. J. The mechanisms of action of commonly used antiepileptic drugs. Pharmacol. Ther. 2001, 90, 21-34.

11. Willmore, L. J. Divalproex and epilepsy. Psychopharmacol. Bull. 2003, 37, 43-53.

12. Chen, Z.; Wang, X.; Wang, H.; Shu-Da, C.; Lie-Min, Z.; Jia-Li, L.; Wen-Ying, S.; Jue-Qian, Z.; Zi-Yan, F.; Yu, Z.; Min, H. Simultaneous determination of valproic acid and 2-propyl-4-pentenoic acid for the prediction of clinical adverse effects in Chinese patients with epilepsy. Seizure 2012, 21, 110-7.

13. Dai, B.; Zhang, H.; Song, Q.; Xu, F. Determination the concentrations of phenobarbital, sodium valproate, phenytoin sodium and carbamazepine in human plasma for simultaneous quatification by HPLC-MS. Chinese J Clin Pharmacol. 2011, 3, 14.

14. Mohammadi, B.; Majnooni, M. B.; Khatabi, P. M.; Jalili, R.; Bahrami, G. 9-Fluorenylmethyl chloroformate as a fluorescence-labeling reagent for derivatization of carboxylic acid moiety of sodium valproate using liquid chromatography/tandem mass spectrometry for binding characterization: a human pharmacokinetic study. J. Chromatogr. B 2012, 880, 12-8.

15. Belal, T. S.; El-Kafrawy, D. S.; Mahrous, M. S.; Muthuraja, S.; Roopan, S. M. Validated spectrophotometric methods for determination of sodium valproate based on charge transfer complexation reactions. Spectrochim Acta Part A. Mol. Biomol. Spectrosc. 2016, 155, 47-53. https://doi.org/10.1016/j.saa.2015.11.008.

16. Sorouraddin, M. H.; Imani-Nabiyyi, A.; Najibi-Gehraz, S. A.; Rashidi, M. R. A new fluorimetric method for determination of valproic acid using TGA-capped CdTe quantum dots as proton sensor. J. Lumin. 2014, 145, 253-8. https://doi.org/10.1016/j.jlumin.2013.07.025.
17. Amini-Shirazi, N.; Ahmadkhamha, R.; Shadma, S.; Ghahremani, M. H.; Abdollahi, M.; Dadgar, A.; Kebriaeezadeh, A. Determination of VPA and its two important metabolites in Iranian overdosed patients. Int. J. Pharmacol. 2010, 6, 854-62.

18. Sobhi, H. R.; Kashtiaray, A.; Farahani, H.; Abrahimpour, F.; Esrafili, A. Quantitation of valproic acid in pharmaceutical preparations using dispersive liquid liquid microextraction followed by gas chromatography flame ionization detection without prior derivatization. Drug Test Anal. 2010, 2, 362-6.

19. European Medicines Agency (EMA) Guideline on Excipients in the Dossier for Application for Marketing Authorisation of a Medicinal Product. London, 2007.

20. ICH Harmonized Tripartite Guideline Validation of Analytical Procedures: Text and Methodology, Q2 (R1). Geneva, 2005.

21. Fouad, A.; Shaykoon, M. S. A.; Ibrahim, S. M.; El-Adl, S. M.; Ghanem, A. Colistin sulfate chiral stationary phase for the enantioselective separation of pharmaceuticals using organic polymer monolithic capillary chromatography. Molecules 2019, 24(5), 833.

22. Fouad, A.; Marzouk, A. A.; Ibrahim, S. M.; Sobhy, M.; Ghanem, A. Functionalized polymer monoliths with carbamylated amylose for the enantioselective reversed phase nano-liquid chromatographic separation of a set of racemic pharmaceuticals. J. Chromatogr. A 2017, 1515, 91-9.

23. Fouad, A.; Ibrahim, D.; Adly, F. G.; Ghanem, A. An insight into chiral monolithic stationary phases for enantioselective high-performance liquid chromatography applications. J. Separat. Sci 2019, 42(14), 2303-40.

24. Elrefay, H.; Ismaiel, O.; Hassan, W. S.; Shalaby, A.; Fouad, A. Simultaneous determination of levetiracetam and preservatives in oral solution formulation using HPLC-Uv method with a programble detection wavelength. Eurasian J. Anal. Chem. 2019, 14(4), $25-31$.

25 Elrefay, H. A.; Ismaiel, O. S.; Hassan, W.; Shalaby, A.; Fouad, A. A validated rapid reversed-phase high performance liquid chromatographic method for determination of risperidone and benzoic acid. Eurasian J. Anal. Chem. 2020, 15(1), emEJAC-00393.

26. El-Adl, S. M.; El-Shanawany, A. A.; Abdel-Aziz, L. M.; Hassan, A. F. HPLC determination of three cephalosporins (cefepime, cefotriaxone and cefotaxime) in their bulk and dosage forms. Asian J. Pharm. Anal. 2014, 4(3), 91-7.

27. Reddy, S. R.; Reddy, K. H.; Reddy, P. M.; Reddy, G. A.; Kumar, M. N.; Sharma, H. K. Reliable GC method for related substances in divalproex sodium drug. J. Chromatogr. Sci. 2017, 55(9), 891-8.

Open Access. This is an open-access article distributed under the terms of the Creative Commons Attribution-NonCommercial 4.0 International License (https:// creativecommons.org/licenses/by-nc/4.0/), which permits unrestricted use, distribution, and reproduction in any medium for non-commercial purposes, provided the original author and source are credited, a link to the CC License is provided, and changes - if any - are indicated. 